\title{
La investicreación artística a partir de las tecnologías del aprendizaje y el conocimiento virtual
}

\author{
Dra. Irma Fuentes Mata \\ Investigadora de Arte y Educación \\ ifuentesmata@msn.com
}

Esta es una ocasión para reflexionar sobre los avances de lo que hace 6 años compartí en el II Congreso, aquí en la UNISON, un trabajo titulado Investicreación Artística, Identidades y perspectivas, que realicé a partir de su fundación en 2012 como representante de la Red de Investicreación Artística. A la fecha, se han realizado muchos proyectos académicos y artísticos bajo la idea de este término que inicialmente se originó al fusionar la investigación y la creación para conceptualizar los procesos que realizan algunos artistas, investigadores o docentes de arte, $\mathrm{y}$ aunque hoy se tienen diferentes visiones, seguramente se seguirá desarrollando por quienes reflexionan, sistematizan, documentan e investigan los procesos de creación artística.

Años antes, cuando publiqué en el texto Integrar la Educación Artística. Política educativa, integración curricular y formación docente colectiva, se estableció la distinción entre «educar por el arte», «educar para el arte» y «educar a través del arte» (Fuentes, 2004), a partir de 2008 inicié la reflexión sobre los enfoques de investigación artística, investigar para el arte, investigar por el arte e investigar a través del arte, que se vio complementada por autores como Cristopher Frayling (1993) y otros de la Escuela de Ámsterdam que ya discutían estos enfoques.

\section{En el marco de la investicreación artística}

A partir de 2013 comenzamos a desarrollar el término «investicreación artística», cuya idea central es que el proceso creativo en el arte también tiene un fundamento en la investigación, aunque muchas veces ese proceso no es visible porque hay una tendencia a presentar el producto y no el proceso artístico, y más aún: sostengo que quien hace investigación artística, realiza un proceso creativo.

Como sabemos, hay muchos tipos de investigación, muchos modelos y muchas formas de generar conocimiento. En el arte también hay muchas formas y algunas de ellas han seguido modelos de otras áreas ajustándose o forzándose a cumplir con necesidades de otros campos, pero cada vez se contribuye más a explorar o validar formas propias para desarrollar el campo artístico.

Para saber más sobre los distintos abordajes que hemos hecho en la Red de Investicreación Artística, existen varias publicaciones y conferencias que pueden ser consultadas, los integrantes de la red hemos puesto nuestro punto de vista en la construcción de este término que atiende la necesidad de dar reconocimiento académico a la investigación en arte que se ha hecho desde siempre en cada una de las instituciones participantes. Más allá de lo que se pueda resolver en las esferas de la administración institucional de las universidades para su legitimación, que también es muy importante, considero que los Seminarios de Metodología de Investigación y Seminarios de Titulación, que están como materia obligatoria en todos los planes de estudio de las licenciaturas, pero específicamente en nuestro campo artístico, tienen peculiaridades 
muy propias. Reconocemos que el proceso de investigar de los estudiantes de arte es diferente en cada caso y que los conocimientos no siempre se obtienen de una sola manera. Si bien hay muchos métodos que nos permiten hacer investigación que son usados en otras disciplinas, siempre queda vacío un espacio sobre la reflexión de los procesos de cómo se crea el arte, por lo que es interesante dar a conocer a otros nuestro proceso.

También es claro que existen metodologías para la creación, metodologías para la formación y metodologías para la investigación, pero en este caso, la propuesta sería desarrollar la metodología para la investicreación artística que consiste en que se dé cuenta del proceso mientras se avanza en la creación artística y se reflexione en las etapas que cada uno avanza, dejando por escrito y de manera sistemática los recorridos de la creación. Si preguntara en este momento: ¿quiénes se consideran creadores? Y les pidiera que narraran el proceso mediante el cual crean, seguramente tendríamos una gran variedad de relatos, que probablemente sean diversos, pero también podríamos encontrar coincidencias o constantes.

Con este gran marco de la investicreación tengo la certeza de que todo artista reflexiona sobre lo que quiere producir y para ello, busca, observa, experimenta, ensaya, codifica, dosifica, elige, selecciona, reconfigura, explora, valora y, al final, genera una propuesta artística. Considero que si pudiéramos detenernos un poco y hacer consciencia de todos los momentos que suceden en el acto creativo, podríamos afirmar que las propuestas creativas-artísticas llevan un proceso metodológico, quizá a veces no es tan sistemático, o quizá tardan más unas etapas que otras, en ocasiones da un giro que se produce otra cosa a la esperada, pero no creo que debamos darle todo el crédito al azar. Pienso que más bien es producto de una elección que el artista investigador toma, de acuerdo con las circunstancias, al contexto, al material con el que cuenta, a los sujetos con los que participa, a las interacciones que se presentan, a las herramientas que tiene ¿y por qué no? También a la iniciativa que integra muchos elementos para decir «ya está listo».

De tal manera que las instituciones en ocasiones nos obligan a entrar en unos formatos y estructuraciones, informes y protocolos que nos hacen olvidar hasta lo que estábamos proponiendo. Por otro lado, si no cumplimos con la actividad académica estandarizada corremos el riesgo de no concluir nunca. Por ello, los Seminarios de Investigación o de Metodología nos indican cómo tenemos que ajustarnos a formular algo comunicable, porque para algunas universidades el producto artístico no es suficiente y por ello hay que elaborar un producto académico. En ocasiones anteriores exponíamos que también había que innovar en los formatos de protocolos o anteproyectos de investigación para el reconocimiento institucional.

Las modalidades de titulación varían en cada universidad e institución y por ahora tenemos algunos ejemplos como el de la Universidad Autónoma de Querétaro donde existen 9 opciones: Tesis individual o colectiva, Promedio, Examen de conocimiento, Memorias de servicio a la comunidad, Estudios de posgrado, Cursos de actualización, Trabajo de investigación, Memoria de trabajo profesional, Libro de prácticas o del maestro. En otras instituciones del INBA, como la Escuela Nellie Campobello, existen opciones para la titulación más acordes al campo de la profesión artística como: Clase Práctica, Montaje Escénico Dancístico, Informe de Práctica Educativa, Informe de Práctica Profesional, Informe de Servicio Social y Tesina. En la Licenciatura en Diseño de la EDINBA están: Tesis, Proyecto de Diseño Integral, Carpeta de Trabajo Profesional, en varias instituciones también se 
incluyen Titulación por Aprovechamiento Académico, o Cursos de posgrado. Sea cual fuere la opción de trabajo académico elegida, en la mayoría hay que entregar un protocolo. Así que es necesario aprender a estructurar un proyecto, ver de dónde se obtiene información, definir sobre lo que se quiere trabajar y elegir una manera de llegar a esos pasos, maneras, secuencias, trayectos para llegar a ese objetivo; es posible que sean explicitados para lograr los objetivos.

Los recorridos que los estudiantes eligen a veces son insospechados, algunos hacen 500 cuartillas de antecedente para llegar a desarrollar su tema en 20 páginas, o algunos piensan que descubrieron hoy el hilo negro y nadie más en el mundo ha pensado en su idea genial o nadie ha escrito nada sobre el tema; así que, como profesora, mi labor es moderar y ubicar al respecto. Sus trabajos son muy interesantes, los títulos de sus investigaciones abordan problemáticas, sociales, ecológicas, políticas, filosóficas, de género, etc. y, de vez en cuando, artísticas.

Entonces son estos últimos a los que me refiero: aquellos que hacen una experimentación a partir del lenguaje mismo del arte, que no hacen investigación solamente sociológica o histórica o educativa o psicológica del arte, sino aquellos que hacen, buscan, se documentan, comparan, experimentan, analizan y elaboran una reflexión referida al arte, a sus obras, a los procesos, a los cambios, a las elecciones, a las experimentaciones y a sus propuestas, amén del terror que puede provocar la titulación.

Debo confesar que después de impartir los seminarios durante 6 años en la Licenciatura en Artes Visuales, es decir, a 12 semestres continuos a 40 estudiantes por semestre, los resultados no han sido tan alentadores. Los pocos trabajos recepcionales

de calidad, se cuentan con los dedos y esto me ha hecho buscar otras estrategias, como ubicarme en su lugar y tratar de percibir lo que los estudiantes perciben, fijarme en qué ponen atención, en qué se concentran y generalmente es en una pantalla, ya sea la de su tableta, su computadora o su teléfono cada vez más inteligente. Entonces al derrumbarse el discurso docente, se percibe que los estudiantes ponen la mayor atención e interés en las redes sociales, se observa que algunos también están interesados en encontrar información sobre su proyecto, dibujando, haciendo tareas, en fin, se comprende que el centro de atención hace mucho que dejamos de ser los docentes y lo que les interesa está en los dispositivos.

Al reconocer que las maneras tradicionales de aprender e investigar en el aula ya no son suficientes para mis estudiantes, que necesariamente recurren a otras fuentes utilizando el internet, les propuse en 2017 que comenzáramos un estudio diagnóstico como parte de la clase, en la que aplicáramos directamente las estrategias metodológicas de la investigación $\mathrm{y}$, a partir de esta actividad, obtuvieran datos sobre sí mismos y sus necesidades de aprendizaje para la investigación. Juntos construímos el instrumento, el diseño y la aplicación la hicieron ellos mismos a través de la redes sociales, se procesó la información en la plataforma surveymonkey.com, obtuvimos datos preeliminares del tiempo que los jóvenes estudiantes de Artes Visuales utilizaban la web, las redes que empleaban, los sitios que visitaban y la información que buscaban, encontramos que pasan mucho más tiempo viendo memes o en Instagram, que leyendo artículos o visitando sitios que les proporcionen algún conocimiento académico. Muchos estudiantes usan la web para relacionarse y establecer redes sociales, pero no todos la usan, o no de la mejor manera, para aprender y generar sus propuestas artísticas.

Motivada por la temática, comencé a recuperar toda la bibliografía posible sobre 
cómo aprendemos a través de los medios tecnológicos. Uno de los aspectos que reveló el estudio, es que hay modos distintos de pensar en los procesos creativos apoyados por herramientas determinadas. Es decir, se puede coincidir o no con la edad, pero lo que sí es común es si tienen acceso al uso de los medios y entendemos que a más temprana

edad, mayor familiaridad y confianza para utilizarlos. Si una niña de 5 años te puede explicar perfectamente el funcionamiento de un programa para jugar a descubrir formas, y te dice «Inténtalo, no tengas miedo. Sí puedes», imaginen lo que un estudiante de la Licenciatura en Arte puede hacer.

Si bien Marc Prensky (2013), dice que somos dos tipos de personas: los nativos y los inmigrantes digitales, esta definición ha evolucionado y si bien algunos nos reconocimos como uno u otros, ahora podemos reconocer que es algo mucho más complejo. Tenemos diferentes tipos de pensamiento y no importa si naciste un par de años antes o después, pero sí es importante si tienes acceso a las tecnologías $y$ te interesa aprender de ellas, relacionarte o producir algo interesante. Ahora la gran mayoría conoce estas tecnologías y si bien se reconoce que muchos todavía no tienen acceso directo, sí tienen contacto con el medio, incluso desde la escuela primaria.

Una de las primeras diferencias que me parece significativa en los procesos de aprendizaje de los que aprendimos antaño es el caso de los académicos que pertenecemos a la red, somos de una generación que tenemos más de 40 o 50 años, conocida ahora como la generación $\mathrm{X}$, que según algunos teóricos se caracteriza por ser adictos al trabajo. En este grupo estamos quienes nos ubicamos en el perfil académico, le damos una estructura al trabajo, registro formal, carta de fundación, proyecto estructurado, gestión de los recursos, establecimiento de compromisos institucionales etc., los proyectos tienen que cumplirse tal cual y tenemos una gran ansiedad por cumplir lo prometido.

El otro grupo de otra generación, son los estudiantes de hoy, quienes se relacionan horizontalmente, radialmente o rizomáticamente. La estructura de relación es diferente, las búsquedas, los intereses y los logros son diversos. La generación Y, conocidos como millennial (1980-1994) y generación Z, centennial (1995-2010), han cambiado el modo pensamiento; son las generaciones que tienen acceso, usan, disfrutan y se comunican con los medios electrónicos, ellos también aprenden y algunos generan conocimiento.

\section{Entre las TICs y las TACs para llegar a la TECAs}

Desde hace más de 20 años, las generaciones ya nacieron con los medios y eso ha cambiado su forma de pensar, comunicarse, estar informados y relacionarse. Es interesante ver cómo se ha visto también el aprendizaje y la producción de conocimiento, es decir, hay personas que usan las TICs y personas que aprovechan las TACs. La diferencia entre ellas es que las llamadas TICS o Tecnologías de la Información y Comunicación, son todos aquellos recursos, herramientas y programas que permiten administrar y compartir la información, es decir, que permiten conectarnos, a diferencia de las Tecnologías del Aprendizaje y Conocimiento Artístico que son fundamentales para este proyecto.

De algún modo, las Tecnologías de la Información y Comunicación (TICS) son como ir al espacio virtual y conocer a muchos amigos, encontrar grupos, comentar, comunicarse en las redes, ver otros mundos. Nos influyen porque nos conmueven, nos solidarizamos, nos enteramos, incluso somos alertados o alentados a participar y a partir de eso suceden muchas cosas buenas y muchas más terribles, pero esto no siempre nos genera un aprendizaje.

Las Tecnologías del Aprendizaje y del Conocimiento (TACs) a diferencia, son 
aquellas que son parte fundamental de los ambientes de aprendizaje, están presentes en el desarrollo de contenidos y sus productos, con elementos didácticos que brindarán oportunidad de obtener nuevos conocimientos y los ambientes digitales los usan como: computadoras personales, tabletas digitales, teléfonos, pizarrones interactivos, pantallas, Smart TV, sistemas de videoconferencias, sistemas para test, laboratorios, simuladores, realidad virtual, consolas de videojuegos y geo-localizadores, impresoras 3D, entre otros y los que se sigan desarrollando; pero todo este hardware no funciona si no tenemos los sistemas software instalados que tienen el sentido, no solo de mostrar, sino de que nuestro pensamiento se desarrolle, se complejice, incorpore nuevos aprendizajes y favorezca nuestros modos de generar conocimiento.

Una experiencia de ese tipo la inaugurábamos en el 2010 en la Maestría en Educación Básica MEB en la Universidad Pedagógica Nacional, Unidad Zacatecas, México. Apoyados en la plataforma moddle, elegimos la modalidad b-learning, pues nos permitía alcanzar a una gran población de estudiantes que vivían en comunidades alejadas, pero teníamos la oportunidad de conocerlos presencialmente en ocasiones programadas. Aunque el programa sigue vigente, las cosas han cambiado mucho desde entonces. En el momento que surgían, los educadores de nivel superior y posgrado nos emocionábamos por ser «innovadores»e introducir estas herramientas tecnológicas a nuestro quehacer docente. Pasamos muchas horas planeando, dosificando, distribuyendo y estableciendo objetivos, metas, contenidos, aprendizajes específicos y rúbricas de evaluación. Fue un proceso enriquecedor, interesante, metódico y laborioso, pero desgastante. Finalmente, estructuramos en las plataformas educativas lo que nosotros como docentes considerábamos que era bueno enseñar: lo correcto, lo apropiado, lo necesario y lo justificable para determinada formación.
Se invirtió una gran cantidad de esfuerzo, tiempo y recursos en búsqueda de la innovación educativa con las llamadas entonces «nuevas tecnologías». Tengo la esperanza de que para alguien esto debió ser provechoso, algunas de esas experiencias se reportan en el informe de investigación de UPN (Fuentes, I. 2011). Todos esos alumnos eran generación $\mathrm{X}$ inmigrantes digitales a los que se les dificultaba el manejo informático, pero que eran muy disciplinados y dedicados.

Tengo muy claro que la época en que desarrollamos sistemas de aprendizaje controlado, con contenidos, dosificados, con estrategias definidas, con pautas a seguir, estrictas, con rúbricas de evaluación y con resultados esperados, han quedado un poco lejos de lo que hoy hacen los estudiantes. Siempre me quedó la duda de que había mucha simulación en esos procesos.

El software se ha desarrollado para proporcionar materiales de enseñanza y, por supuesto, actividades de aprendizaje digital. Los recursos multimedia están presentes, pero también existen los museos virtuales, los documentos digitales, los glosarios, las revistas en línea y los sitios web educativos, los videos en trasmisión en tiempo real de conciertos y puestas en escena, en fin, todos estos aportan al conocimiento y algunos de manera muy especializada. También entre ellos están los recursos que permiten a los artistas aprender y no solo tener y/o generar conocimiento, sino también crear.

Ahora sostengo la idea de que los estudiantes de arte, además de los lenguajes especializados de arte, utilizan un tercer o cuarto lenguaje para algunos que es el manejo natural de estas tecnologías, así sus consultas se van especializando en sitios específicos y por supuesto, sus creaciones. Por lo menos en el ámbito de la música y las artes visuales los medios digitales les permiten enriquecer su conocimiento de manera expansiva.

Supongo que pronto tendremos que hablar de una tercera categoría que yo defi- 
niría como Tecnologías para la Expresión y Creación Artística. En lo que se reconoce o legitima esta idea, ya podemos sostener que los estudiantes y egresados de arte tienen otros modos de comprender las formas de crear a través de las tecnologías. Por ello, inicié la investigación Escenarios virtuales para el aprendizaje del arte, con el interés de centrarme en estudiar los procesos de apropiación del conocimiento o de recuperación de la información de los estudiantes para enriquecer y formar su visión artística, teniendo en cuenta que la formación artística va más allá de las aulas.

El objetivo general de la investigación es caracterizar los escenarios virtuales académicos para el aprendizaje de artes visuales que utilizan los estudiantes y egresados de nivel superior. Después de hacer un diagnóstico de los hábitos de uso de las redes sociales y el internet entre los estudiantes de $8 .^{\circ}$ semestre y egresados, que habían cursado la materia de Seminario de Titulación en el grado de Licenciatura en Artes entre 2012 y 2017, pudimos tener un panorama de las prácticas de navegación en la web de los artistas en formación. Este estudio se inició en el contexto de la ciudad de Querétaro, México, y hemos reportado los datos de las prácticas de uso de los dispositivos en otras ponencias y publicaciones de eventos académicos, como el del VII Encuentro Nacional de Investigación y Documentación de Artes visuales de Cenidiap (Fuentes,I. 2018) y el Encuentro de la Red de Investicreación Artística en Burgos, España, y el III Congreso de Pensamiento y Comunicación en Sevilla, España. (Fuentes, 2018)

Entre los objetivos específicos de la investigación, está el de contextualizar el aprendizaje virtual actual en la formación del artista visual. Así, tenemos claro que los estudiantes de arte viven condiciones diferentes a los artistas de antaño, pues actualmente el acceso a la información y a las imágenes es mucho más amplio. Las universidades ahora cuentan con plataformas que permiten el libre acceso, y ya no solo se consulta en ordenadores, sino cada vez más en los dispositivos móviles desde cualquier sitio.

$\mathrm{Si}$ bien es necesario tener fundamentos artísticos y metodológicos para producir arte, es también importante ver que en la evolución de las formas de aprender y expresar, las tecnologías han aportado mucho, así el pensamiento tecnológico y artístico va cambiando y evolucionando. Algunos podrían quedar en el nivel básico de «aprendo más de óleo con un tutorial de YouTube que en los 4 años de carrera» palabras textuales de uno de mis alumnos, o subir un nivel más en la reflexión de lo que hacemos y emprender un proceso investigativo apoyado por las tecnologías para crear productos artísticos.

Ante los retos que se plantea la escuela actual, estamos de acuerdo con Elmor y City ,citados por Ángel Pérez Gómez (2012), quienes proponen un escenario satisfactorio de la escuela en la era digital denominado «aprendizaje de código abierto».

...este escenario se propone en la escuela en un territorio abierto, compitiendo con otros servicios e instituciones por el interés de los aprendices y familias, sin el rol determinante en la definición de lo que constituye el aprendizaje y el conocimiento válidos, ni tampoco en la definición del ritmo, secuencia y estructura de plan de estudios cerrados. En este escenario abierto, saturado de posibilidades, el aprendiz con la ayuda de los docentes que actúan como tutores va definiendo su propio currículum en función de sus intereses y propósitos, al mismo tiempo que va configurando progresivamente la singularidad de su propio proyecto personal, social y profesional (Pérez, A. I. 2012:18).

Al final de cuentas, profesores, asesores o tutores de trabajos de titulación debiéramos hacer esto, ser acompañantes del proceso de descubrimiento y orientadores respetuosos del proceso de construcción personal de un artista, facilitando ciertas estructuras o sugiriendo caminos para de- 
sarrollar el potencial de cada estudiante y dejando muy claro que el proceso de construcción del conocimiento sobre una experiencia artística es tan válido como cualquier otro conocimiento en otros campos. Así la escuela o en este caso, la universidad, cumpliría con lo que señala Pérez Gómez: «Provocar en la escuela el interés, la curiosidad, la imaginación y la creatividad así como provocar la pasión por el conocimiento, la cultura, las artes, las humanidades y las ciencias requiere de una manera de enseñar y aprender muy diferente» (2012:19).

El escenario contemporáneo que debe desarrollar la

...capacidad de utilizar y comunicar de manera disciplinada, crítica y creativa las herramientas simbólicas. Aprender a observar, indagar, contrastar, experimentar, argumentar, decidir y actuar. Capacidad de utilizar el conocimiento distribuido entre las personas, las instituciones y sobre todo, en la nube y las redes temáticas de manera rigurosa y crítica, siendo conscientes de la caducidad, parcialidad y contingencia y de manera creativa imaginando nuevos modos de interpretación y actuación (Pérez, 2012, p:29).

Respecto a los espacios con los que ahora podemos contar para aprender y comunicarnos, Innés Dussel advierte que:

...las tecnologías digitales han creado un nuevo escenario para el pensamiento, el aprendizaje y la comunicación humanas, han cambiado la naturaleza de las herramientas disponibles para pensar, actuar y expresarse. La cultura digital supone una reestructuración de lo que entendemos por conocimiento, de las fuerzas y los criterios de verdad y de los sujetos autorizados y reconocidos como productores de conocimiento (citada por Pérez, 2012, p:61).

\section{Datos del estudio diagnóstico}

Los buscadores a los que acuden los es- tudiantes para recuperar información académica son: Google Académico, Redalyc, Academia.edu, Scielo y Eric, estos lugares permiten encontrar los listados de publicaciones, ya sea por autores, temas, identificar revistas y artículos y localizar bibliografía especializada. Pero también se interesan en sitios de arte que les permiten ampliar su visión sobre la imagen los museos, las galerías o novedades artísticas y, sobre todo, se conectan a las páginas o blogs individuales de los artistas con los que buscan tener un acercamiento directo. Estos blogs de artistas les parecen interesantes pues conocen la producción y establecen un contacto con los artistas a través de los comentarios

El otro aspecto es que buscan tutoriales, cursos online, academias artísticas e incluso, universidades virtuales que les permitan tener un conocimiento más amplio sobre su profesión, así se enteran de que hay otras maneras de hacer arte, otras formas de obtener el conocimiento y buscan tener a su alcance esas experiencias, aunque se pierden un mucho al navegar y se revisan y reformulan sus propuestas constantemente. Si bien las personas que interactúan en las redes tienen una manera de actuar y pensar diferente, hay que cultivar prácticas adecuadas para frenar los efectos negativos de las tecnologías.

\section{Un caso de investicreación artística en arte digital}

Para esta etapa del trabajo, elegí mostrar cómo algunos estudiantes aprovechan su formación dentro de la escuela pero no solo se quedan ahí, sino que generan un proceso de búsqueda de su propio lenguaje artístico, intentan recuperar información y conocimientos para desarrollar su visión artística.

Al proponer a mis egresados un ejercicio de reflexión para reconocer su proceso creativo les sugiero que expliquen cuál son las etapas que atraviesan para desarrollar su producción artística, que iden- 
tifiquen los momentos de ese proceso como: dónde hacen la búsqueda, con qué experimentan, cómo eligen, cómo exploran con las herramientas digitales y cuáles son, y si son de software libre.

Hay procesos metodológicos para la investicreación en el arte visual-digital, como el caso de uno de mis estudiantes egresados, Alberto Ledesma Equihua, a quien asesoré para su trabajo de titulación. Al inicio se interesó en la fotografía y desarrolló una investigación sobre el Glitch que es el error digital, posteriormente, fundamentó su obra digital en una serie de «errores» o exploraciones que dan cuenta de un constante proceso de experimentación y búsqueda de un lenguaje propio que se refiere al manejo de fractales, reiteraciones, distorsiones, etc.

En entrevista, explica su proceso: «comienza mediante la apropiación de conceptos y estéticas, yo creo que para crear, primero hay que explorar todo lo posible para después mezclar lo que necesitas para ejecutar tu idea». A partir de las preguntas, él reflexiona sobre el concepto el ser creativo, el proceso de búsqueda, el análisis de los conceptos para la obra, los materiales, los programas y las aplicacio- nes que utiliza; la diferencia entre usar métodos tradicionales o métodos digitales y las aplicaciones o el software libre que utiliza, así, su obra genera propuestas nuevas en la pantalla: modifica, explora y ya cuando está satisfecho de haber logrado el concepto, pasa a la impresión.

Este es un ejemplo de lo que los jóvenes están haciendo con las tecnologías y el arte, más allá de que seamos más proclives a las técnicas tradicionales o a las técnicas digitales podemos ver que los principios de búsqueda, acopio de información, conceptualización, experimentación, elección, reconfiguración, adaptación, reconfiguración de lo establecido para generar nueva producción artística o nuevo conocimiento, son parte de un aprendizaje constante y de permitir la investicreación artística.

En general, la investicreación artística nos sirve para recordar que existe un proceso sistemático y riguroso para producir el arte y es importante dejar evidencia del trabajo sin dejar de lado la creatividad, el disfrute y el goce que provoca crear algo nuevo a partir de un conocimiento fundamentado.

\section{Referencias}

Frayling, C. (1993) Research in Art and Desing. London,U.K: Royal College of Art Research Papers.

Fuentes, I. (2004) Integrar la Educación artística. Política educativa, integración curricular y formación docente colectiva. México: Plaza y Valdés/ Cenidiap.

Fuentes, I. (2011) La formación profesional en el posgrado, Maestría en educación básica en la modalidad b-learning. Documento interno Informe de investigación México:UPN,

Fuentes, I. (2015) "InvestiCreación artística identidades y perspectivas." en Arte, entreparéntesis num.1 Diciembre. México: Unison, www.arteentreparéntesis. unison.mx

Fuentes, I (2018) "Navegar en internet o atrapados en la red. Aprendizaje y pensamiento artístico a partir del uso de tecnologías de información y comunicación" en Arte, Educación y pensamiento digital. Educar, crear y habitar en la quinta pared, Caeiro, M. Coord. España: Egregius. www.egregius.es p.35-48

Fuentes,I. (2018) “Pensar, aprender y formar a partir de las imágenes". En La vorágine de las imágenes. Accesos, circuitos, controles, archivos y autorías en el arte. Memoria del VII Encuentro de investigación y Documentación de Artes visuales. México: SC INBA Cenidiap

Pérez, Á. (2012) Educar en la era digital. Madrid: Morata

Prensky, M. (2013) Enseñar a nativos digitales. México: SM 